\title{
Globalization and Spread of English Homogenization or Hegemonization
}

\author{
Fawwaz Al-Abed Al-Haq \\ Yarmouk University, Irbid, Jordan
}

\author{
Amer Hatamleh \\ Yarmouk Universuty, Irbid, Jordan
}

\begin{abstract}
The purpose of this study was to investigate the status of English Language in Jordan in light of the current globalization. The population of the study represented the Yarmouk University students in Jordan. The sample was 400 students randomly drawn from the population, 389 students responded seriously, and 11 were excluded. The sample consists of 65 master students and 324 bachelor students. A five-point scale questionnaire consisting of 55 items was developed by the researchers . The data obtained were processed and statistically computed and analyzed 200 using the SPSS (Statistical Product and Service Solutions) package. Means and standard deviations were employed in the tables. The finidings of the study indicate that the Yarmouk University students a gree that leaning English is not an indication of Americanization. They regard the use of English a means of enrichment of the one's personality and cultural experience. Learning English to them is a mere importance in the light of the current globalization. The study recommends that universities, schools, and educational institutions should pay more attention to the ESP (English for specific purposes) programs. Planners should also pay more attention to the negative sides of globalization.
\end{abstract}

Keywords: linguistic globalization, homogenization, hegemonization, language planning

\section{Preface}

Globalization is such a huge worldwide phenomenon that its consequences are clearly noticed in all dimensions which relate to and affect human lives. In this sense, the globe has become a very small place indeed as a result of instantaneous communication.

Globalization is regarded as the outcome of human innovation and technological progress. It refers to the increasing integration around the world. The term sometimes refers to the movement of people and knowledge across the international borders. Also, it is worth mentioning here that there are broader political, environmental, cultural, and linguistic dimensions of globalization.

Globalization, furthermore, refers to the quickening of the completion of the international movement of trade, and financial, cultural, and linguistic extension beyond national borders.

Mazrui (1998) defined globalization as the following: "It consists of processes that lead toward global interdependence and the increasing rapidity of exchange across vast distances” (p. 1). 
Pennel (1998, p. 1) viewed globalization as a social process in which the constraints of geography on social and cultural arrangements recede and in which people become increasingly aware that they are receding waters contents that in a truly globalized world, only one culture would prevail and no central governmental structure would exist.

Kubursi (1999, p. 2) stated the following: Ideologies and technology have combined to dismantle national borders and barriers... they are part of process known as globalization, whereby the boundaries and imagination of space have become independent of location and time.

It is worth mentioning that the linguistic dimension of globalization is not less important than the other dimensions since language is the only carrier of culture and a main source of pride.

It is claimed that the linguistic globalization is the new linguistic mask whereby a particular language or languages are promoted at the expense of the other ones, and in which new cultures and ideologies are obtained as the national and the original ones are no more able to satisfy the new linguistic global needs. Such claim must be deeply studied and investigated, because if such claim is right, linguistic globalization will, then, be regarded as a threat to the world's linguistic and cultural dimensions.

Linguistic globalization, according to the researchers, refers to the prevalence of one language to the extent in which that dominating language is the main channel of information and knowledge worldwide. Moreover, such a prevailing language, English in this case, is regarded as the linguistic monitor showing the movement of both trade and technology all over the world.

According to the current situations in which most of the world live, in light of the current globalization, language planning with no doubt carries the slogan of seizing opportunities. This is because we always think that, particularly in these economically, politically, and linguistically challenging times, it is necessary to maintain a realistic and far-sighted view of potential successes.

Language planning is an ideal partner for government and government-authoritative bodies in the linguistic industry, since language, nowadays, is exported just like any other product worldwide.

In this paper, the researchers seek to elucidate the consequences of linguistic globalization and to find out whether the global linguistic intentions can be utilized to serve the promotion of other languages equally or is it a matter of linguistic inequality?

The statement of the problem: The study attempts to investigate the phenomenon of globalization in general and the linguistic globalization in particular. The study aims at investigating the nature of linguistic globalization, the objectives, goals, problems, consequences, and the factors that enhance linguistic globalization.

\section{Significance of the Study}

Despite the fact that the study has its main roots in the sociolinguistic field of study, information is still scanty. In Jordan, there have been few studies dealing with such linguistic phenomenon. Thus, the researcher believes that this study will be significant since it will provide a new vision illustrating the linguistic consequences of globalization.

\section{Purpose of the Study}

The primary purpose of the present study is to investigate the status of English language in Jordan 
particularly in light of the current globalization. It is hoped that the study will find answers to the following questions: (1) To what extent does globalization imply linguistic dependency?; (2) To what extent is English going to be competing with or invading national and foreign languages?; (3) To what extent is English an imperialistic language?; and (4) Does the adoption of a new language like English lead to the adoption of a new culture, and does that lead to homogeneity?.

\section{Method}

Deals with the method employed in this study. It describes the population, the sample of the study, and the technical instrumentation of the questionnaire (data collection, data analysis).

\section{Population}

The population of the study represents the Yarmouk University students in Jordan. The number of its students is about 21,000 students. The population of the study is classified according to the major variables of the study: sex, specialization, and level of education.

\section{Sample}

A sample of 400 students is randomly drawn from the population. Out of the whole sample only 389 students responded seriously and 11 students were excluded because of their incomplete answers.

According to this sampling design and based on the hypothesis of the study, the respondents of the sample include both sexes, different specializations, and different levels of education.

The researchers exact that the sample represents the population. The sample consists of two major main groups: 65 master students and 324 of bachelor junior and senior students.

The sample, composed of different educational levels (136 economics, 110 science, and 143 English). Moreover, the sample includes both sexes: 183 males and 206 females.

\section{Data Collection Procedures}

To achieve the objectives of the study, a five-point scale questionnaire consisting of 55 items was developed by the researcher based on Al-Abed Al-Haq and Smadi (1996a, 1996b). The questionnaire was designed and written in Arabic to avoid any difficulties in understanding each item.

The questionnaire is composed of three sections. The first section includes four personal and demographic variables relating to the respondents themselves. The variables are: level of specialization, sex, education, and personal attitude.

The second section includes 51 items measured upon five-point Likert scale. These items are directed towards revealing the respondents' views and attitudes regarding the phenomenon of linguistic globalization.

The third section also contains two more question measuring the validity, reliability, comprehensibility, and adequacy of responding to the questionnaire.

To each item the students were asked to show the extent to which whether they SA (strongly agreed), A (agreed), U (undecided), D (disagreed), or SD (strongly disagreed).

The 53 statement questionnaire covers five attitudinal dimensions. They include: (1) Americanization or Westernizaiton and the use of English (include items 5, 6, 7, 9, 10, 11, 18, 19, 23, 29, 36, 37, 46, 47, and 53); (2) national identity (includes items 8, 20, 34, and 39); (3) attitudes towards linguistic globalization (include items 4, 12, 13, 14, 15, 16, 17, 28, 30, 31, 32, 33, 35, 38, 42, 43, 44, 48, 50, 51, and 52); (4) need for English 
(includes items 1, 2, 3, 21, and 22); and (5) language planning and English language promotion (include items 24, 26, 27, 40, 41, 45, and 49).

The questionnaire was distributed by the researcher himself within five days. The researcher visited the questioners during their class times; so they would be motivated to answer the questionnaire seriously. The respondents, also, were given enough time to fill out the questionnaire.

\section{Data Analysis}

After the questionnaires were distributed, completed, and returned to the researcher, the responses were coded, and frequencies and percentages were estimated. The data obtained were processed and statistically computed and analyzed using the SPSS (Statistical Product and Service Solutions) package. The researcher used the following statistical procedures:

(1) Means and standard deviations which were employed in the tables concerned with the attitudinal dimensions of the respondents. The five-point Likert scale is used here, ranging from strongly agree (mean $=4.26$ ) to strongly disagree $($ mean $=1.91)$.

(2) T-test analysis was used to find out the range of correlation between the first and second hypothesis and the core of the study. Then, a one-way ANOVA test was made the comprehensibility and adequacy of the questionees' responses to the questionnaire is presented in Table 1.

Table 1

Comprehensibility and Adequacy of the Items of the Questionnaire

\begin{tabular}{lllll}
\hline Question & $\begin{array}{l}\text { Fully } \\
\text { Understood (\%) }\end{array}$ & $\begin{array}{l}\text { Generally } \\
\text { understood (\%) }\end{array}$ & $\begin{array}{l}\text { Not fully } \\
\text { understood (\%) }\end{array}$ & $\begin{array}{l}\text { Missing cases } \\
\text { (\%) }\end{array}$ \\
\hline $\begin{array}{l}\text { What is your opinion regarding your understanding of } 20.8 \\
\text { the items of the questionnaire? }\end{array}$ & 66.6 & 10.5 & 8 \\
$\begin{array}{l}\text { What is your opinion regarding your responses to the } \\
\text { items of the questionnaire? }\end{array}$ & 81.3 & 68.9 & 15.7 & 12 \\
\hline
\end{tabular}

\section{Findings and Discussion}

The present study is designed to explore the phenomenon of linguistic globalization in a socio-linguistic framework. It aims at revealing the attitudinal dimensions and views of the respondents towards such a phenomenon in Jordan.

This section presents the findings and discussion of the study. The findings of the research are introduced after being processed by using statistical analyses.

\section{Americanization}

This dimension covers the following aspects:

Enrichment of personality and culture, a means of advancement of Jordan, English as a means of linguistic and cultural homogeneity, spread of English as an indication of linguistic imperialism, promotion of English as a point of fact of linguistic encroachment, using or learning English as an indication of Americanization, use of English as a source of danger Arabic and other languages, learning English as a national duty.

Opening the discussion with getting a look at item 1 with a mean 3.79 and standard deviation 1.07, reveals that the majority of the respondents (72.5\%) agreed to the focal point of the item; they highly believe that English is a channel of personal and cultural enrichment. 
This finding can be reasonably justified in the light of the fruits and privileges gained by the use of English as a means of mobility and social prestige. It goes without saying that English nowadays, more specifically in light of the current globalization, is one of the major channels, if not the only one, through which people from different poles of the globe can communicate.

Item 3 with mean 3.39 and standard deviation 1.26 is concerned with the imperialistic purposes behind spreading English. It is clear that $50.2 \%$ of the participants agreed, 26.8\% disagreed, and $23.1 \%$ were undecided. Such an appeal to view the spread of English from an imperialistic corner is, perhaps, due to the political and military situations that the Jordanians had undergone in the past. It seems that the people suffered a lot, as Jordan had been under the British mandate and occupied by the British colonizers.

In the case of learning English as a national duty to protect Jordan from cultural backwardness, item 4 with mean 3.47 and standard deviation 1.28 shows that $63.3 \%$ agreed, while $28.3 \%$ disagreed. Such a finding may well be explained in light of the current correlation between English as the world language and the world's cultures and technology.

Only $12.4 \%$ of the participants agreed that learning English entails following, imitating, and adopting the American and/or the Western values, and patterns of behavior. Whereas 78.7\% of them disagreed, and 9.0\% were undecided. This high percentage of disagreement shows that the respondents are fully aware of the language itself and its speakers. So, this being the case, we can say that the respondents are not against the language per se.

This is also reinforced in responses to item 14 with the mean 2.70 and standard deviation 1.25. 64.4\% agreed and $42.2 \%$ agreed respectively, while 26,5\% disagreed and 35.0\% disagreed. This agreement can be explained in light of the neutrality of English as a reliable carrier for all cultures, values, and ideologies representing various nations from all over the world. But such an expansion of English to the world's various domains is sometimes considered as a negative and fatal point, that which is clearly expressed by the responses to items 7 and 8 , where 43.2\% agreed that globalization causes English to be a source of danger to the status of Arabic here in Jordan and the other modern languages such as French, Italian, etc., as well, and $49.9 \%$ agreed respectively.

It obviously seems that the participants are sentimentally and ideologically adhered to Arabic since the majority of them disagreed to go with such stream of thought. This point is further exacted in responses on item 15 with mean 2.37 and standard deviation 1.41. This is perhaps due to the fact that there is nothing evil or good languages that make one language better than the other ones, or make us take a particular language for granted as the best linguistic choice.

It is obvious that the relationship hold between them is merely reciprocal and the benefit is absolutely mutual, i.e., that both sides utilize the slope that joins them to complete each other. Regarding item 13 concerning the use of English in the early stages of education, the responses to this item show that the majority of the participants (65.1\%) give a positive stand toward the importance of English as a school-subject in the early stages.

\section{National Identity}

This section sheds light on the Arabic identity and the impact of the spread of English on Arabic language standing as a symbol of Arabic unity and existence.

In response to items 16 and 17 with means 2.19 and 2.45 and standard deviations 1.18 and 1.24, we find that 
only $18.3 \%$ agreed and $23.4 \%$ agreed respectively. While the majority of the respondents $76.1 \%$ disagreed and $67.1 \%$ disagreed. This disagreement clearly shows that the use of English, according to the participants does not entail a care for or imitation of the western culture and values, neither is a threat to the Arab identity.

The disagreement, once again, is probably interpreted as an appeal to view English as the world linguistic wheel which reduces the need for translators and interpreters of so many different languages, i.e., English is a matter of linguistic compromise.

This reduction, according to the participants, has nothing to do with the cultural corruption, but it can be used to transfer their own culture to all the world instead.

While the agreement of the participants may be due to the current situations, undergone by all people, regarded as raw materials of the new American world, globalization in this sense. This agreement is also elucidated in response to item18 with mean 3.20 and standard deviation 1.24, nearly the half of the respondents (49.6\%) agreed that the consistent expansion of English especially in light of the current globalization entails or implies obliteration of the features of the other languages, whereas $37.6 \%$ of the respondents disagreed and the rest of $12.9 \%$ were undecided.

\section{Linguistic Globalization}

This section presents a series of views regarding the participants' attitudes towards linguistic globalization. Concerning item 20 which states that globalization is the hand giving a strong push to English to become a crucial part of our life, the majority of the respondents (78.7\%) agreed upon this point, while $11.3 \%$ disagreed.

In regard to item 21 with mean 3.52 and standard deviation $0.94,42.2 \%$ of the respondents agreed upon the debate of English competition as a rival to the other languages, whereas $12.6 \%$ of them disagreed with this line of thought, and $35.2 \%$ were undecided.

This agreement is probably explained as an appealing view of the participants looking at globalization as a steering power turning English into a "booming industry".

This is further approved in responses to item 40 viewing linguistic globalization as a matter of linguistic replacement. According to the majority of the participants (62.2\%), the consistent advancement of English entails the replacement of the other languages and their defeat to compete nationally or internationally, whereas $24.2 \%$ disagreed.

This agreement is perhaps, best elucidated where dialects are encouraged by those responsible for promoting English, since dialects are described as defeated languages and as separating lines.

In Jordan, it is different from that argument of dialectal dimension, but it is rather concerned with creating the appropriate environment where English always attempts to replace or weaken the functional status of Arabic within its national borders; English has been juxtaposed to the Arabic language in so many domains and sectors, and it rather replaces Arabic in others.

In response to item 22 with mean 3.32 and standard deviation 1.12, 46.1\% agreed that linguistic globalization is a channel of invasion. Whereas $25.2 \%$ of them disagreed with this stream of thought.

All of these things are negatively reflected on the status of Arabic and consequently lead to the usurpation of the Arabic linguistic rights in various domains in its own heartland.

Since English is the most economically, politically, and supported language, the respondents may believe 
that English will compete with the other languages, because it is the only one obtained, and invade them by penetrating their homelands using the above-mentioned domains as its steel shield, whereas $31.3 \%$ disagreed and $21.6 \%$ disagreed.

There are some people who strongly link the promotion and prevalence of the American or western values, ideologies, habits, and cultures with linguistic globalization. In responses on items 24 and 25, the majority of the respondents (38.9\% and 49.3\%) agreed upon viewing linguistic globalization as a fertile land for the American cultural, ideological, and habitual seeds. Thus, according to the participants, linguistic globalization is a marketer and promoter of a one-way culture, ideology, and way of thinking are the American ones endorsed in the linguistic dimension of globalization.

It is not surprising then, that the superiority of the English language (linguistic globalization) entails the superiority of the American culture, values, ideologies, and way of life and thinking, since it is hardly possible to adopt English as the only linguistic choice (available and sometimes permitted) without being influenced by the values and ideologies, or without assimilating the cultural senses embedded in the language, especially if this culture or ideologies are supported by the other dimensions of globalization.

All this is further evident in responses to items 35 and 36 . The responses show that $55.5 \%$ agreed and $49.9 \%$ agreed with this line of thought. This agreement entails further support of the argument that the linguistic dimension of globalization is a threat to Arabic culture, civilization, and values. Such an argument is perhaps explained by saying that the consideration of English as a "panacea" is an evidence of socio-linguistic and a cultural disease in itself.

The majority of the responses may be explained in light of the fact in that culture is the main life preserver of language, and as language is inseparable from the cultural dimension, we find, then, that the relation between both of them is really symmetrical and reciprocal.

This disagreement reflects the participants (43.4\% and 46.7\%) little hope of the prospect of a unifying global language or culture. But they are rather eager to encourage and assert the plurality of cultures in global, because cultural or/and linguistic superiority leads to the ascendancy and prevalence of particular culture and linguistic products that are consumed by the world public at the end. Whereas the agreement of the respondents (22.7\% and $25.2 \%$ ).

This is highly noticed here in Jordan, particularly in some parts of the capital Amman, and in most of the universities in Jordan, that the young people nearly blindly copy or imitate the American way of thinking, talking, eating, and even dressing, since such imitations, according to them, come to be an indication of social prestige and modernization.

Furthermore, we cannot ignore the role played by the American academic institutions and schools all over the world since they aim at spreading the American cultural and social stream of thought as the most popular American export.

Thus, using English in such academic and cultural sectors, as well as in other sectors such as, entertainment, fashion, products, food, advertisement, tourism, etc., leads to the prevalence of the American culture and values. Whereas the participants' disagreement is possibly explained as they draw a dividing line between the argument regarding English as container of the world divers cultures, and the counter argument presenting English as a cultural linguistic monster. 
The disagreement may also be probably explained in light of the consideration that English is the language that gives access to power, because it is the first choice that steers the world linguistic cycle.

In closing this section, item 37 with a mean score 3.04 and standard deviation 1.19 shows that the respondents are divided into two halves; $41.1 \%$ agreed that linguistic globalization implies linguistic marginalization. This is perhaps, due to the English language monopolization of the world linguistic market, i.e., the domination and hegemonization of English in the world's various sectors.

This is supported by Zachary (2001), who said that uniqueness is greater sold to a wider market. This is further noticed in the loss of the world linguistic ground to the English language, considered as the language of power.

$39.1 \%$ disagreed with this line of thought. This may be explained as the participants adjuration or suit to view the necessity for global language as they assign a great importance to it. English, in this sense, operates globally to serve the interests of all.

\section{The Need for English Language}

This section covers the following: the necessity of and need for English language in assimilating technology, spreading knowledge and information, getting job opportunities, acquainting others with the history and civilization of Jordan, and the need for English in introducing TV and radio programs for foreigners.

It is noticed that the reaction of the majority toward the usefulness of the English language is quite evident: 79.1\% strongly observed the need for English in understanding and assimilating modern technology.

Additionally, 52.2\% agreed that English is the most ideal channel through which knowledge and information spread worldwide, whereas $40.6 \%$ disagreed with this stream of thought.

This disagreement is expected, since the respondents are aware of the linguistic natural diversity, i.e., that it is not a matter of restriction to one linguistic choice, taken for granted, to be the only source of knowledge, and information but, according to the participants, there are multi-linguistic choices (languages) which can function as well as English does.

The high percentage of responses (85.0\%) to item 42 reveals an understanding of the utility, workability, and feasibility of the English language. This is, perhaps, best explained in light of the intrinsic link or slot joining English with technology, economy, commerce, trade, and cultural domain.

In Jordan, the position is the same. It is obvious that most people, particularly the young are economically and instrumentally motivated to learn English because learning English, to them, is a way to get better jobs, and increases their incomes.

High percentages of agreement have been shown in responses to items 43 and 41 , since $84.1 \%$ agreed and 87.4\% agreed that English is a channel of both acquainting others with the history, civilization, and antiquities of Jordan, and presenting our programs to foreigners inside and outside the country.

\section{Language Planning and English Language Promotion}

This section covers the following aspects: the role of language planning in protecting and promoting national languages, the role of the US known as the world power and the American agencies in spreading and promoting English, and the role of globalization in making English as the world lingua franca and its impact on the other languages. 
Regarding both items 46 and 47 concerning the role of language planning in protecting and promoting the national languages, we find that $77.1 \%$ agreed and $87.6 \%$ agreed respectively, whereas $4.7 \%$ disagreed and $4.7 \%$ disagreed with this line of thought.

This majority reflects the respondents' awareness and consciousness toward the role of language planning in drawing policies and ideologies to attain particular goals at the end. This is best illustrated by Cooper's (1989) saying:

A theory of language planning would enable us to explain language planning initiatives, the means chosen to effect the goals, and the outcomes of the implementation. We would understand, in other words, the motivation for a particular status, corpus, and acquisition goals and for choosing particular means and the reasons that the means do or do not effect the goals within a given social change... That language planning should serve so many covert goals is not surprising. Language is the first institution experienced by the individual but also because all institutions are built upon its regularity... to plan language is to plan society. (p. 182)

Such a valuable framework is best introduced by Al-Abed Al-Haq (1998). He stated that: "Arabicization planning is a process, according to the researchers point of view, which refers to activities and deliberate efforts to plan for corpus, status and acquisition of Arabicization, adoption of Arabicization” (p. 59).

Thus, the respondents are highly motivated to consider language planning as a source of policies and ideologies to be planned in order for the Arabic language to acquire a special and an advanced position among the other languages at both levels, the national and the international. Also, language planning, according to the participants, sets limits for the other foreign languages within the national borders.

Regarding both items 48 and 49 concerning the economic power behind the spread and promotion of English as a global language, it was found that $74.3 \%$ agreed that the economic dimension plays a part in the entrenchment of English as a global language, and $44.4 \%$ agreed respectively. Whereas $14.9 \%$ disagreed and $24.9 \%$ disagreed with this stream of thought.

This majority is, perhaps, best explained in light of the fact that the countries which are economically developed are linguistically developed too.

This point is further emphasized in response to item 50 with a mean score 4.20 and standard deviation 1.00. The responses show that $79.7 \%$ agreed that the United States has mere control over the world's various dimensions, while $8.7 \%$ disagreed. This majority is reasonably justified in light of the world current situations.

This is further evident in responses to item 51, since the majority of the respondents (75.3\%) agreed upon the major role played by the American cross-border companies and actors to promote their English language as one of their main exports and to expand their privileges all around the globe, where as $10.0 \%$ disagreed.

This reveals the American linguistic monopoly in maintaining inequality and legitimizing the domination and hegemonization of the American English language.

\section{The Hypotheses of the Study}

\section{Hypothesis 1}

The first hypothesis states that there is attitudinal correlation between linguistic globalization and sex. This means that the researcher expects that the responses on the items relating to the phenomenon that the 
study deals with varying from one participant to another depending on his/her sex. In testing this hypothesis which expects a significant attitudinal correlation between the linguistic dimension of globalization and sex variable, a $T$-test analysis is made to calculate the mean, standard deviation, $T$-value, and 2-tail significant level (Sig.).

Table 2

T-test Results Between Linguistic Globalization and Sex

\begin{tabular}{lllllll}
\hline Variable & No. of cases & Mean & SD (standard deviation) & T-value & $d f$ & 2-tail Sig. \\
\hline Male & 183 & 166.8634 & 27.564 & 2.52 & & 012 \\
Female & 206 & 160.4175 & 22.868 & & 387 & \\
\hline
\end{tabular}

According to the expectation of the researcher, Table 2 shows that there is a significant correlation between the linguistic dimension of globalization and sex. Therefore, the first hypothesis is valid. Such a difference between both sexes was expected in advance, since the use of English is deeply connected with sex and social level (prestige). Thus, these tenets give the females a different attitude toward the use of English in particular, and linguistic globalization in general, than the one obtained from the males.

\section{Hypothesis 2}

The second hypothesis states that there is attitudinal correlation between specialization and linguistic globalization. This means that the study expects that the responses of the participants to the items concerning the phenomenon of linguistic globalization differ from one individual to another based on his/her specialization. In testing this hypothesis which expects a significant relationship between linguistic globalization and the specialization variable, one-way ANOVA analysis is used where the mean, standard deviation, F-ratio, and F-probability are calculated.

Table 3

ANOVA Results Between Linguistic Globalization and Specialization

\begin{tabular}{llllll}
\hline Group & No. of cases & Mean & SD & $F$-ratio & $F$-probability \\
\hline Economics & 136 & 161.7426 & 24.6685 & 4851 & 6160 \\
Science & 110 & 164.6545 & 26.1012 & & \\
English language & 143 & 164.469 & 25.5186 & & \\
& 389 & 163.4499 & 25.3586 & & \\
\hline
\end{tabular}

Defeating the researcher expectation, Table 3 shows that there is no statistically significant correlation between linguistic globalization and the participants' specializations. Thus, the second hypothesis is invalid. This means that the attitudinal dimensions or responses towards linguistic globalized do not differ from one individual to another based on his/her specialization.

\section{Hypothesis 3}

The third hypothesis states that there is a significant attitudinal correlation between linguistic globalization and the respondents' level of education. This means that the study expects that individuals' views concerning the phenomenon investigated in this study (linguistic globalization) differ from one participant to another based on his/her level of education.

In testing the validity of the third hypothesis, a $T$-test is made, as well as the $T$-value and the 2-tail Sig. 
Table 4

T-test Results Between Linguistic Globalization and the Level of Education

\begin{tabular}{lllllll}
\hline Variable & No. of cases & Mean & SD & $T$-value & $d f$ & 2 -tail Sig. \\
\hline Master & 65 & 172.7385 & 28.133 & 3.28 & 387 & 001 \\
Bachelor & 324 & 161.5864 & 27.388 & & & \\
\hline
\end{tabular}

According to Table 4, there is a significant correlation between the individuals responses on linguistic globalization in Jordan and their level of education. This indicates that the stands towards linguistic globalization are different from one individual to another based on his/her level of education.

\section{Conclusions}

The findings of the study indicate that the Yarmouk University students agree that learning English neither is an indication of Americanization, nor implies an imitation or/and adoption of the American culture. The students regard the use of English as a means of enrichment of the one's personality and cultural experience. Learning English, to them, is a mere importance, especially in light of the current globalization for assimilating modern technology, a wider range of job opportunities and higher and better status jobs.

Regarding the relationships between the use of English and national identity, it was found that the majority of the individuals believe that the use of English is not negatively reflected on their attachment and adherence to their national and cultural identity.

Regarding the wide use of English, the findings show that globalization has the lion's share in enhancing and enforcing the ground of the English language status to give it an out-stand from the other languages, and to be the main, if not the only, language of economy, technology, commerce, politics, and cultural exchange. This point arouses the participants' doubt to suspect the loyalty of such a linguistic choice, English in this sense. Based on this tenet, it was found that linguistic globalization entails implicitly or explicitly linguistic dependency.

English foreign words, especially the American ones, in conversations in everyday life made by the young people, particularly the university students.

The participants highly believe that linguistic globalization implies linguistic replacement, whereby English replaces the other languages just like Arabic in Jordan. This is clearly seen in the use of English in official documents, passports, driving licenses, car number plates, and even in the Arabic local newspapers.

Regarding the promotion of English, it was found that the participants highly believe that the consistent promotion of English and the distinguished and global status of English is never an accident, but is rather planned to maintain inequality. This promotion is due to the American penetration of the world's economic, political, military, and commercial dimensions.

In closing this section, the researchers conclude by presenting the participant's belief in the role of language planning in protecting and promoting their native language (Arabic) from any linguistic invasion.

\section{Implications}

The findings of this study show that the students of Yarmouk University are, to a large extent, aware of the interactional linguistic, cultural, economic, political, and social situations they live; they are merely conscious 
of the implicit relationships that link these dimensions, as each dimension of globalization aims at strengthening the ground of the other one.

On the basis of the findings of this study, Jordanian students are neither Americanized nor Anglicized due to the use of English; their national identity and cultural unity are not affected by the virtue of English; and their adherence to their own language does not became corrupted by the impact of English.

English as a neutral linguistic choice is not a direct vehicle of colonization in light of the current globalization, it is an assist, carrier, and investment to reflecting on our ideas, culture, polices, and political educational stream. Linguistic globalization can fruitfully be utilized if the dominance of English is not at the expense of Arabic language.

An interesting implication that can be drawn is that globalization, as a major umbrella, offers the Arabic language a great chance to be promoted as a commercial product available everywhere.

\section{Recommendations}

(1) In their attempt to influence the attitudes, beliefs, and behaviors of others, the sociolinguistic policymakers and planners should pay more attention to fatal and negative sides of globalization.

(2) From a language planning point of view, schools, institutions, and universities should pay more attention to the ESP (English for specific purposes) programs.

(3) More research in the area of globalization should be undertaken in the light of the following proposals: (a) Other studies might examine the role of language planning in promoting Arabic, so that it can be one of the modern competing languages globally; and (b) Moreover, further studies should increase the size of the sample to include people from different parts of the country, and from different social and economic backgrounds.

\section{References}

Al-Abed AL-Haq, F. (1998). Toward a theoretical framework for the study of planning Arabicization. In S. Abdulla, D. Gaym, \& S. Mohammad (Eds.), Issues in translation. Jordan: Irbid National University, and Translators’ Association.

Al-Abed Al-Haq, F., \& Smadi, O. (1996a). Spread of English and westernization in Saudi Arabia. World Englishes, 15(3), $307-317$.

Al-Abed Al-Haq, F., \& Smadi, O. (1996b). The status of English in the Kingdom of Saudi Arabia (KSA) from 1940-1990. Berlin/New York: Mounton deGruyter.

Campbell, K. (1996). The world rushes to speak and write “American” English. Christian Science Monitor, 88(196), 10-18.

Cooper, R. (1989). Language planning and social change. Cambridge: Cambridge University Press.

Kubursi, A. (1999). Sustainable human development under globalization: The Arab challenge. Human Development Studies Series, 10.

Mazrui, A. A. (1998). Globalization, Islam, and west: Between homogenization and hegemonization. The American Journal of Islamic Social Science, 15(3), 1-13.

Pennell, J. A. (1998). Globalization: Myth or reality? The American Journal of Islamic Social Sciences, 15(3), 107-127.

Phillipson, R. (1996). Linguistic imperialism: African perspective. ELT Journal, 50(42), 160-178. 